\title{
CHARACTERIZATION OF HEAT WAVES: A CASE STUDY FOR PENINSULAR MALAYSIA
}

\author{
Wayan SUPARTA ${ }^{1 *}$ and Ahmad Norazhar Mohd YATIM ${ }^{2}$
}

DOI: 10.21163/GT_2019.141.11

\begin{abstract}
:
The present work aims to investigate the characteristics of heat waves in Peninsular Malaysia based on the Excess Heat Factor (EHF) Index. This index was calculated based on the daily maximum and minimum temperatures over nine meteorological stations in Peninsular Malaysia during the period 2001 to 2010. The selected station is representing all of the states in Peninsular Malaysia. Statistical analysis found that the highest of the EHF happened at the Kuala Lumpur station in 2002 with an index of $9.1^{\circ} \mathrm{C}^{2}$ and the lowest was in Alor Setar in 2006 with an index of $0.1^{\circ} \mathrm{C}^{2}$. The EHF moderate was found at Kuantan with an index of $4.2^{\circ} \mathrm{C}^{2}$. Moreover, the longest heat wave with 24 days has happened in Ipoh, Perak with amplitude of $29.4^{\circ} \mathrm{C}-33.0^{\circ} \mathrm{C}$. Most of the heat wave characterized in Malaysia occurred during the El Nino events especially moderate El Nino in 2002 until 2005, and 2010. The Southeast, northeast and west part of Malaysia experience the highest average heat wave activity. These results indicated that the heat wave conditions in Peninsular Malaysia are anxious and this requires immediate investigation because it has a direct impact on agriculture, particularly health, economic, and human being.
\end{abstract}

Keywords: Heat wave, Excess heat factor, Climate change, Characteristics, Peninsular Malaysia.

\section{INTRODUCTION}

Heatwave is one of the most threatening natural hazards and can adversely affect ecosystem, infrastructure, human health, and social life (Zuo et al., 2014). Populations are very vulnerable to changes in heat wave attributes and extreme heat wave events can increase human morbidity and mortality rates (Anderson \& Bell, 2011). Previous studies show that heat wave is responsible for more deaths than all other natural hazards in Australia (Coates et al., 2014) and climate risk in Romania (Bocancea, 2018). Although there is no standard definition of the heat wave, it can be referred as a period of consecutive days of abnormal weather. Heat waves are increasing globally due to the effects of climate change. Numerous studies have indicated that climate change is expected to exacerbate the heat wave events, particularly more frequent in their duration and intensity (Coumou \& Rahmstorf, 2012). Asia region also experiences adverse effects of climate change. The Intergovernmental Panel on Climate Change (IPCC, 2013) states that South Asian countries, will be at the greatest risk for the emergence of heat waves. The heat wave impacts could be enlarged and significant from region to region, for example in developing countries such as Malaysia.

The heat wave event is one of the uncommon natural hazards observed and has had a significant impact on Malaysia. However, the heat wave mitigation has not been taken seriously by most governments and non-governmental organization (NGOs) working on

\footnotetext{
${ }^{1}$ Pembangunan Jaya University, Department of Informatics, South Tangerang City, Banten 15413, Indonesia, Corresponding author: wayan.suparta@upj.ac.id

2 Universiti Malaysia Sabah, Kota Kinabalu,88400 Sabah, Malaysia,norazahar@ums.edu.my
} 
monitoring and disaster risk reduction. The impact of heat wave in Malaysia is currently under-reported and it is difficult to assess information such as morbidity, mortality, and economic consequences. Although the heat wave events in Malaysia have not been extensively investigated, in recent years there have been a number of studies focusing on climate change and temperatures. Wai et al. (2005) used 50 years (1951-2001) of temperature data set to study the global warming trend in Malaysia and found that the annual mean temperature increased from 0.99 to $3.44^{\circ} \mathrm{C} / 100$ years. A study by Makerami et al. (2012) found that an acceptable thermal condition in outdoor spaces of a hot and humid climate of Malaysia is less than $34^{\circ} \mathrm{C}$ where the comfort condition is in the early morning (9-10 am) and late afternoon (4-5 pm). Mohd Salleh et al. (2015) also found that most of the stations across Peninsular Malaysia showed an inclination toward a temperature above the annual mean surface temperature of $26^{\circ} \mathrm{C}$ to $28^{\circ} \mathrm{C}$ and with high annual precipitation values $(1200-2400 \mathrm{~mm}$ ). From the preliminary studies above provide clues that the investigation of heat wave and their characteristics will be useful to improve human understanding and awareness.

This study will focus on the analysis of heat wave characteristics in Peninsular Malaysia from 2001 until 2010. We choose an Excess Heat Factor (EHF) method across different climates, which is an ideal method to normalize the climatology variation in heat wave from a hazard point of view (Perkins \& Alexander, 2013). This method is introduced to create a universal method for heat wave definition and measurement (Nairn et al., 2009). The EHF index capable provides results which more focused on the pattern of heat wave frequency, duration, amplitude, and a number of days in the past decade. The results of the investigation of heat wave will provide a better understanding and importance of climatology events and early warning systems especially during extreme weather in Malaysia.

\section{DATA AND METHODS}

Section 2.1 describes details about the data set used in this study and Section 2.2 describes the method conducted to determine the heat wave events and characterization.

\subsection{DATA}

The daily maximum temperature $\left(\mathrm{T}_{\max }\right)$ and minimum temperature $\left(\mathrm{T}_{\min }\right)$, both in ${ }^{\circ} \mathrm{C}$ units for the period 2001-2010 were obtained from the Malaysian Meteorological Department (MetMalaysia). Data on temperature were based on the availability of the meteorological data at nine stations across Peninsular Malaysia. The meteorological station in Johor Bahru and Malacca is represent the Southwest of Peninsular Malaysia; Kuala Lumpur and Perak is for the West; Penang and Perlis is for the Northwest; Pahang, Kelantan, and Terengganu is for the East. All the selection stations represent the urban, suburban, and industrial area. In this study, we focused on Peninsular Malaysia for the year 2001-2010 where the previous study has shown that there were El Nino events recorded globally during this study period. Table 1 compiling the detail of each station and Figure 1 depicts the location of the stations.

The figure shows that Peninsular Malaysia or West Malaysia is located in Southeast Asia between $1^{\circ} \mathrm{N}-6^{\circ} \mathrm{N}$ and $101^{\circ} \mathrm{E}-105^{\circ} \mathrm{E}$, which covers an area of $130,598 \mathrm{~km}^{2}$. The climate of Peninsular Malaysia is characterized by two monsoon regimes namely the Southwest Monsoon (SWM) and the Northeast Monsoon (NEM). The SWM usually influenced by low-level southwesterly winds begins in May and ends in August. For NEM, 
it is dominated by northeasterly winds that cross over the South China Sea. This season usually begins in November and usually lasts between 3-4 months the following year in February. During NEM, the exposed areas on the eastern part of Peninsular Malaysia receive heavy rainfall while the SWM is a drier period for the whole country, particularly for the other states of the west and north coast of Peninsular Malaysia. For a larger view, Peninsular Malaysia surrounded by two large oceans which are the Pacific Ocean to the east and the Indian Ocean to the west. This situation makes Peninsular Malaysia climate strongly influenced by natural climate variability associated with these oceans (Tangang et al., 2012).

Table 1.

Nine selected stations in Peninsular Malaysia

\begin{tabular}{llllll}
\hline No. & Station & Region & Classification & Longitude & Latitude \\
\hline 1 & Johor Bahru & Southwest & Industrial & $103^{\circ} 40^{\prime} \mathrm{E}$ & $1^{\circ} 38^{\prime} \mathrm{N}$ \\
2 & Malacca & Southwest & Suburban & $102^{\circ} 15^{\prime} \mathrm{E}$ & $2^{\circ} 16^{\prime} \mathrm{N}$ \\
3 & KLIA & West & Urban & $101^{\circ} 42^{\prime} \mathrm{E}$ & $2^{\circ} 43^{\prime} \mathrm{N}$ \\
4 & Ipoh & West & Urban & $101^{\circ} 05^{\prime} \mathrm{E}$ & $3^{\circ} 18^{\prime} \mathrm{N}$ \\
5 & Butterworth & Northwest & Suburban & $100^{\circ} 16^{\prime} \mathrm{E}$ & $5^{\circ} 18^{\prime} \mathrm{N}$ \\
6 & Alor Setar & Northwest & Suburban & $100^{\circ} 24^{\prime} \mathrm{E}$ & $6^{\circ} 12^{\prime} \mathrm{N}$ \\
7 & Kota Bharu & East & Urban & $102^{\circ} 18^{\prime} \mathrm{E}$ & $6^{\circ} 10^{\prime} \mathrm{N}$ \\
8 & Kuala Terengganu & East & Suburban & $103^{\circ} 06^{\prime} \mathrm{E}$ & $5^{\circ} 23^{\prime} \mathrm{N}$ \\
9 & Kuantan & East & Industrial & $102^{\circ} 15^{\prime} \mathrm{E}$ & $3^{\circ} 30^{\prime} \mathrm{N}$ \\
\hline
\end{tabular}

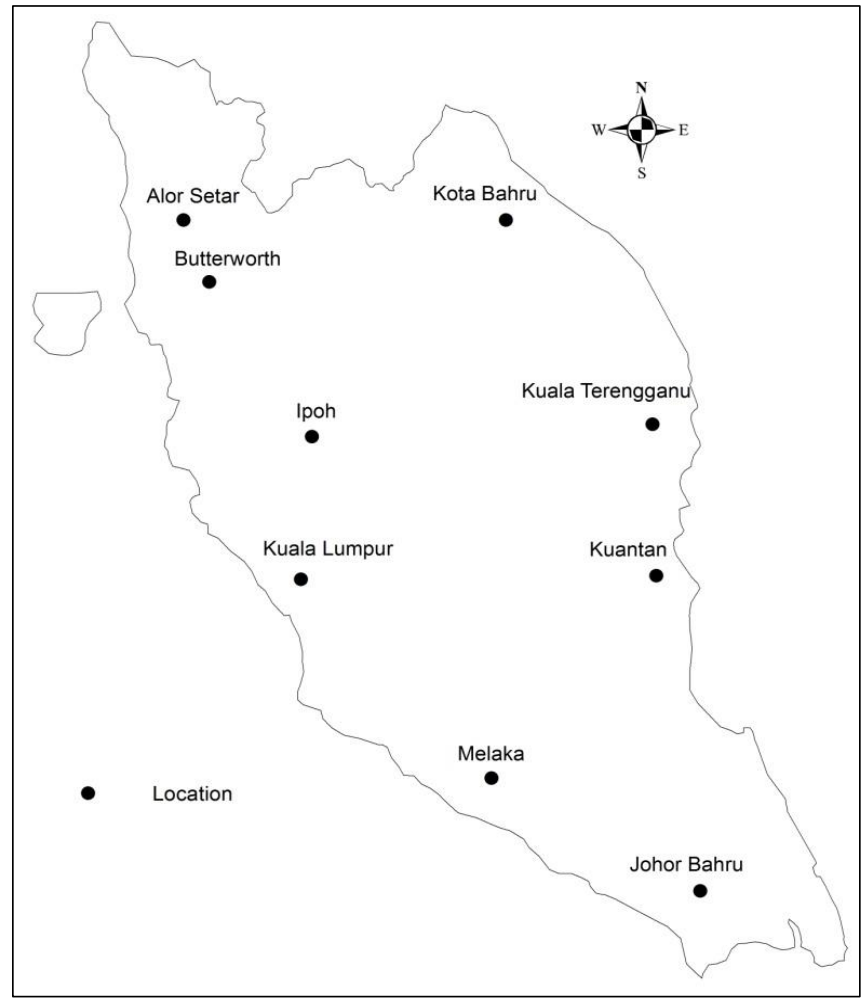

Fig. 1. Locations of nine selected stations in Peninsular Malaysia. 


\subsection{METHODS}

There are a number of indices to determine the heat wave that has been developed based on the difference parameter. In this study, we chose the EHF index method to determine the heat wave events, which was developed by Nairn and Fawceet (2013).The EHF was determined based on the combined effect of two excessive heat indices, i.e. excess heat index significance $\left(\mathrm{EHI}_{\mathrm{sig}}\right)$ and excess heat index acclimatization $\left(\mathrm{EHI}_{\mathrm{accl}}\right)$

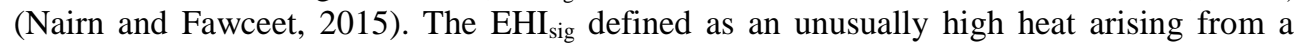
high daytime temperature to unusually high overnight temperature. It can be measured by comparing directly three days period (TDP) of daily mean temperature (DMT) against a climate reference annual temperature $\left(95^{\text {th }}\right.$ percentile). For the calculation $95^{\text {th }}$ percentile, we used 10 years period climate reference at each particular location. From the results, if the TDP average is higher than the climate reference, then each day in this period is marked as unusual warm or excess heat event. The units of $\mathrm{EHI}_{\text {sig }}$ are degree Celsius $\left({ }^{\circ} \mathrm{C}\right)$ and the equation is given by (Nairn \& Fawcett, 2013).

$$
\mathrm{EHI}_{\text {sig }}=\frac{\left(\mathrm{T}_{\mathrm{i}}+\mathrm{T}_{\mathrm{i}+1}+\mathrm{T}_{\mathrm{i}+2}\right)}{3}-\mathrm{T}_{95}
$$

where $T_{i}$ is the DMT on day $i$ and $T_{95}$ is the $95^{\text {th }}$ percentile of DMT for the climate reference period of 2001-2010. In addition to $\mathrm{EHI}_{\text {sig }}$, DMT is the average of $\mathrm{T}_{\max }$ and $\mathrm{T}_{\min }$ as given by

$$
\mathrm{T}=\left(\mathrm{T}_{\max }+\mathrm{T}_{\min }\right) / 2
$$

The second heat index is $\mathrm{EHI}_{\mathrm{accl}}$ which defined as a period of heat that is warmer than the recent past (on average). Acclimatization to higher temperatures depends on the characteristics of human physical adaptation that takes between two and six weeks, which involved adjustment of physiological cardiovascular, endocrine, and the renal systems (Nairn \& Fawcett, 2015). In this index, 30 days has been used as the period required for determining acclimatization. $\mathrm{EHI}_{\mathrm{accl}}$ can be measured by determining the difference between the same three-day-averaged DMT compared against the average DMT over the preceding 30 days. The units of $\mathrm{EHI}_{\text {accl }}$ is also in ${ }^{\circ} \mathrm{C}$ and the index is given by (Nairn \& Fawcett, 2013).

$$
\mathrm{EHI}_{\mathrm{accl}}=\frac{\left(\mathrm{T}_{\mathrm{i}}+\mathrm{T}_{\mathrm{i}+1}+\mathrm{T}_{\mathrm{i}+2}\right)}{3}-\frac{\left(\mathrm{T}_{\mathrm{i}-1}+\cdots+\mathrm{T}_{\mathrm{i}-30}\right)}{30}
$$

where Ti is the DMT on day $\mathrm{i}$. $\mathrm{EHI}_{\mathrm{accl}}$ is an anomaly of three day of DMT with respect to the previous 30 days. Positive $\mathrm{EHI}_{\mathrm{accl}}$ means the three days are warmer than the recent past (on average). Then, the EHF as in equation (4) is calculated based on the combination of these two indices, i.e. $\mathrm{EHI}_{\mathrm{sig}}$ and $\mathrm{EHI}_{\mathrm{accl}}$, which provides a comparative measure of frequency, duration, amplitude, and spatial distribution of a heat wave event. The unit of $\mathrm{EHF}$ is ${ }^{\circ} \mathrm{C}^{2}$.

$$
\mathrm{EHF}=\mathrm{EHI}_{\text {sig }} \times \max \left(1, \mathrm{EHI}_{\mathrm{accl}}\right)
$$

where 1 in equation 4 is basically necessary to make a small positive value at least for a short heat wave. EHF calculation incorporates the effects of humidity on heat tolerance 
indirectly by using the mean, rather than the maximum daily temperature. It provides a comparative measure of intensity, load, duration and spatial distribution of a heat wave event, and has a strong signal-to-noise ratio (Guyton \& Hall, 2000). Universal understanding the impact of a heat wave on human health are varied, but mostly shows that vulnerable population for the following three days is more sensitive and affected (Keggenhoff et al., 2014). As a result, the heat wave is defined as a period of at least three days with EHF > 0 (positive value) with the combination of excess heat and heat stress with respect to the local climate ${ }^{13}$. Then, we use the EHF index results to calculate annual values of four heat wave characteristics based on Fischer and Schar (2006) as below.

1. The heat wave amplitude (HWA) is the peak of EHF value from the hottest heat wave event of the year.

2. The heat wave number $(\mathrm{HWN})$ is the annual number of heat wave events.

3. The heat wave frequency (HWF) is the annual frequency of days contributing to the heat wave events (the sum of participating heat wave days per year).

4. The heat wave day (HWD) is the duration of the longest annual heat wave event (must be $\geq 3$ days).

To characterize a spatial distribution of each heat wave in Peninsular Malaysia, we used the inverse distance weighted (IDW) interpolation method in ArcGIS version 10.3 software. ArcGIS software provides tools like spatial analysis tools for spatial data analysis either raster or vector data that apply statistical theory and technique. Figure 2 shows the overall methodology that has been conducted in this study. The next section discusses the result and discussion of the finding.

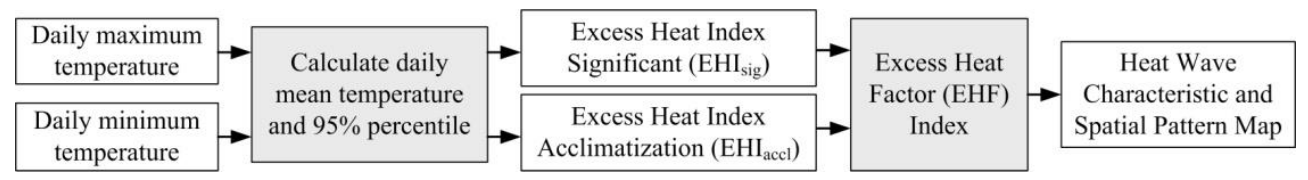

Fig. 2. Summary of research methods.

\section{RESULT AND DISCUSSION}

Heat wave conditions exist when the EHF is positive at least three consecutive days while a single or double positive EHF value does not define a heat wave (Perkins \& Alexander, 2013). Based on the EHF index, the heat wave events for all stations from 2002 to 2006 and 2010 have been identified to determine the characteristics of HWN, HWF, HWD, and HWA. Figure 3 illustrates the variation of the EHF index across Peninsular Malaysia during the period 2001-2010. Referring to Figure 3(a), the EHF index in Johor Bahru shows the heat wave events happened from 2002 to 2004 and 2010 with the highest EHF index in May 2002 with $7.0^{\circ} \mathrm{C}^{2}$. Figure 3(b) presents the EHF index for Melaka with heat wave event happened from 2002 to 2005. The highest $\mathrm{EHF}$ index is $1.3^{\circ} \mathrm{C}^{2}$ in April 2002. Meanwhile, Figures 3(c) and 3(d) show the EHF index for KLIA and Ipoh with heat wave event happened in the year 2002, 2003, 2009 and 2010 for KLIA while from 2002 to 2005 and 2010 for Ipoh. These two locations show the highest EHF index compared to others with EHF index $9.1^{\circ} \mathrm{C}^{2}$ for KLIA and $7.9^{\circ} \mathrm{C}^{2}$ for Ipoh and both happen in May 2002. For Northwest area in Figures 3(e) and 3(f), the heat wave event in Butterworth was happened from 2002 to 2004 , and 2010 with the highest EHF index is $3.5^{\circ} \mathrm{C}^{2}$ in May 2002 while Alor Setar shows heat wave event happened from 2002 to 2006 and 2010 with the highest index is $1.8^{\circ} \mathrm{C}^{2}$ in March 2010. Meanwhile, the heat wave events over East 
Peninsular Malaysia for Kuantan and Kuala Terengganu in Figures 3(g) and 3(h) indicated the heat wave event happened from 2002 to 2004, and 2010. It slightly differences for Kota Bahru in Figure 3(i) with the heat wave event was happened from 2002 to 2005, and 2010. The highest of the EHF index for Kuantan is $4.2^{\circ} \mathrm{C}^{2}$ and Kuala Terengganu is $3.0^{\circ} \mathrm{C}^{2}$ which both happen in June 2002 while for Kota Bahru is $3.4^{\circ} \mathrm{C}^{2}$ happened in May 2002.
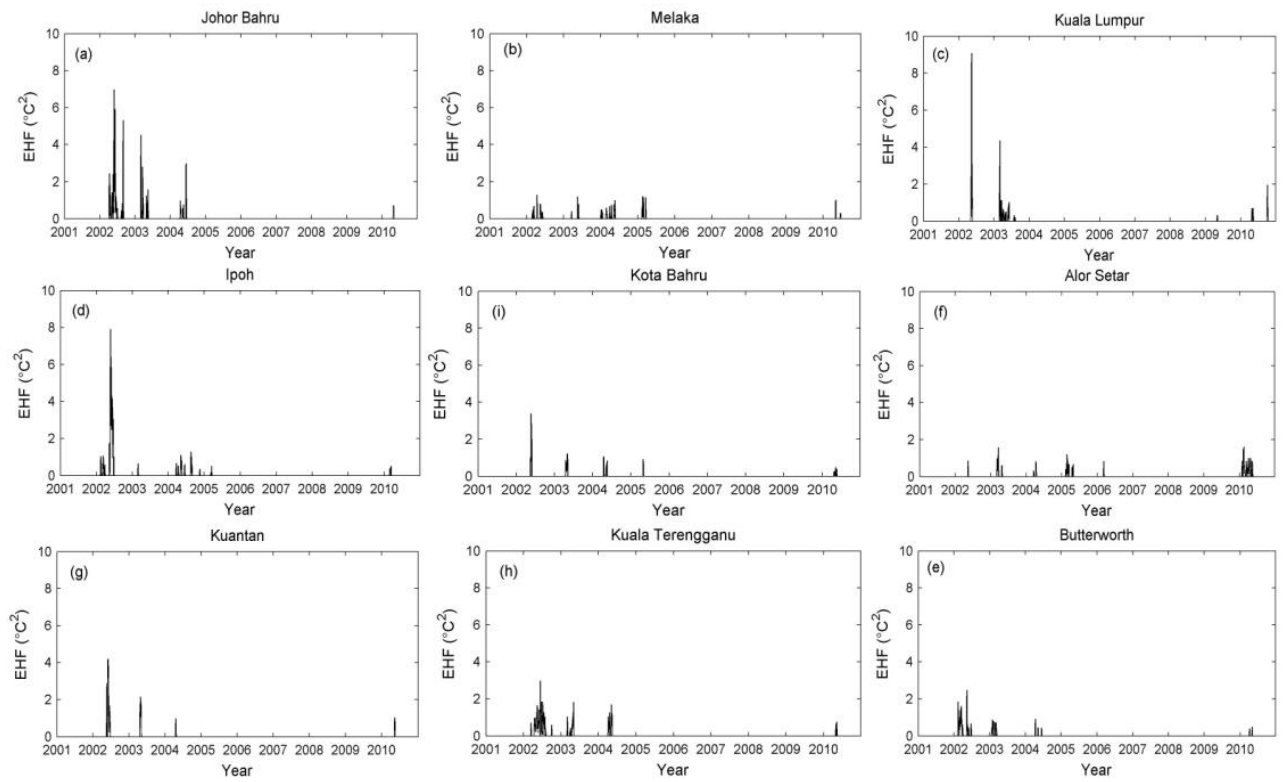

Fig. 3. Variation of EHF index (a) Johor Bahru, (b) Melaka, (c) Kuala Lumpur, (d) Ipoh, (e) Butterworth, (f) Alor Setar, (g) Kuantan, (h) Kuala Terengganu and (i) Kota Bahru.

From the result, the heat wave event almost happened during southwest monsoon (SWM) which is between March and July. Major heat wave events with the highest EHF index happened in 2002 for all locations except Alor Setar in 2010. The critical value recorded during the study period may be due to severe dry spells in East Malaysia that have been recorded during the El Niño events which are three driest years (1963, 1997, and 2002) for Peninsular Malaysia (MMD, 2009). We can conclude that the variation of heat wave events for the most area in Peninsular Malaysia is affected by El Nino during the period 2001-2010. Abul and Gazi (2016) compiled El Nino event and classified during 1952-2010 globally which indicated moderate El Nino during 2002-2003 and 2009-2010 while weak El Nino event happened during 2004-2005 and 2006-2007. The result of this study also shows the difference of EHF index refers to the urban, industrial and suburban area. Urban and industrial areas such as Kuala Lumpur, Ipoh, Kuantan, Kota Bahru, and Johor Bahru recorded higher EHF index than the suburban area (Alor Setar, Kuala Terengganu, Melaka, and Kota Bahru). For urban and industrial regions, it is exposed to more heat wave events compared to the suburban or rural area. The effect of heat in urban areas is probably due to the result of the interaction of synergies such as surface moisture deficiency in urban areas, low wind speed, and also a difference in ambient temperature between the two areas (Fisher et al., 2007).

Table 2 shows the summary of the heat wave characteristics over Peninsular Malaysia during the period 2001-2010. From the Table, the standard annual mean surface 
temperature for this country is ranged from $26^{\circ} \mathrm{C}$ to $28^{\circ} \mathrm{C} 22$. For the value of 95th percentile in each location, Kuala Lumpur and Ipoh were the highest with $30.2^{\circ} \mathrm{C}$ and the lowest was in Kuala Terengganu and Melaka at $29.5^{\circ} \mathrm{C}$. For $\mathrm{HWN}$, the most heat wave cases happened in Johor Bahru with 1.8 events/year from April until June 2002 with 8 cases recorded. The lowest of HWN were observed in Kuantan with 0.6 events/year where on April 2004 is one case recorded. For HWF, it happens at a similar location like HWN, where the highest value is 14.5 days/year and the lowest value is 6.6 days/years. For HWD, the highest sum of participating heat wave days happened in a similar location as HWN and HWF, where during 2002 happened with 74 days from April until June and the lowest is 3 days in April 2004 for Johor Bahru dan Kuantan, respectively. The longest duration was at Ipoh from 7 May until 30 May 2002 (24 days) with an average of 4.7 days/year and the shortest was at Kuantan with 1.4 days/year (3 April until 5 April 2004). Over the considered period of HWA, the highest was recorded in Kuala Lumpur with $1.6^{\circ} \mathrm{C}^{2} /$ year and the lowest was in Alor Setar with $0.5^{\circ} \mathrm{C}^{2} /$ year. Based on the EHF calculation, the strongest and the weakest amplitude heat wave peaks were recorded in Kuala Lumpur on 17 May until 21 May 2002 with index range $2.7 \mathrm{C}^{2}-9.1^{\circ} \mathrm{C}^{2}$ and in Alor Setar from 3 March until 6 March 2004 with index range $0.1^{\circ} \mathrm{C} 2-0.2^{\circ} \mathrm{C}^{2}$, respectively.

Table 2.

Peninsular Malaysia heat wave characteristic for the period 2001-2010: 95\% Percentile, HWN, HWD, HWF, HWA

\begin{tabular}{lccccc}
\hline Station & $\begin{array}{c}\mathbf{9 5}^{\text {th }} \\
\text { Percentile } \\
\left({ }^{\circ} \mathbf{C}\right)\end{array}$ & $\begin{array}{c}\text { HWN } \\
(\text { no. of } \\
\text { event/year })\end{array}$ & $\begin{array}{c}\text { HWF } \\
\text { (days/year) }\end{array}$ & $\begin{array}{c}\text { HWD } \\
(\text { days/year })\end{array}$ & $\begin{array}{c}\text { HWA } \\
\left({ }^{\circ} \mathbf{C}^{2} / \text { year }\right)\end{array}$ \\
\hline Johor Bahru & 29.4 & 1.8 & 14.5 & 3.1 & 1.3 \\
Melaka & 29.5 & 1.6 & 13.9 & 3.7 & 0.6 \\
KLIA & 30.2 & 1.4 & 11.6 & 3.7 & 1.6 \\
Ipoh & 30.2 & 1.7 & 14.3 & 4.7 & 1.1 \\
Alor Setar & 30.0 & 1.7 & 14.2 & 4.0 & 0.5 \\
Butterworth & 30.0 & 1.6 & 13.8 & 2.6 & 0.7 \\
Kuantan & 29.6 & 0.6 & 6.6 & 1.4 & 0.9 \\
Kuala & 29.5 & 0.8 & 7.2 & 1.7 & 0.7 \\
Terengganu & & & & & 0.7 \\
Kota Bharu & 29.8 & 0.9 & 8.1 & 1.8 & 0.7 \\
\hline
\end{tabular}

Figure 4 shows the general spatial distribution of heat wave characteristic for Peninsular Malaysia. HWN Figure 4(a) showed the highest average value which concentrated in the southwest and northwest of Peninsular Malaysia (1.5-1.9 event/year) and the lowest value is observed in the east part of Peninsular Malaysia (0.50-0.70 event/year). Similar to HWN, the highest average value for HWF ( $>14$ days/year) can be found in the southwest and northwest and the lowest 6.0-8.0 days/year) is in East Peninsular Malaysia (Figure 4(b)). In Figure 4(c), HWD shows the longest average duration of 4 to 7 days per year which predominantly located in the west and northwest of Peninsular Malaysia. The shortest heat waves (1-2 days/year) are observed in the east part of Peninsular Malaysia. Figure 4(d) shows the HWA with the highest $\left(1.3^{\circ} \mathrm{C} 2-1.5^{\circ} \mathrm{C} 2 /\right.$ year $)$ and the lowest $\left(0.5^{\circ} \mathrm{C} 2-0.7^{\circ} \mathrm{C} 2 /\right.$ year $)$ is located in west part and some part of the Northeast (Alor Setar) and southeast (Melaka) of Peninsular Malaysia. From these spatial distributions, the heat wave events are dominated by seasons in the southeast, northeast, and west parts of Malaysia where the majority of heat waves has happened during the 
southwest monsoon season. This characteristic is also similar to what happened in Iran (Esmailnejad, 2016).
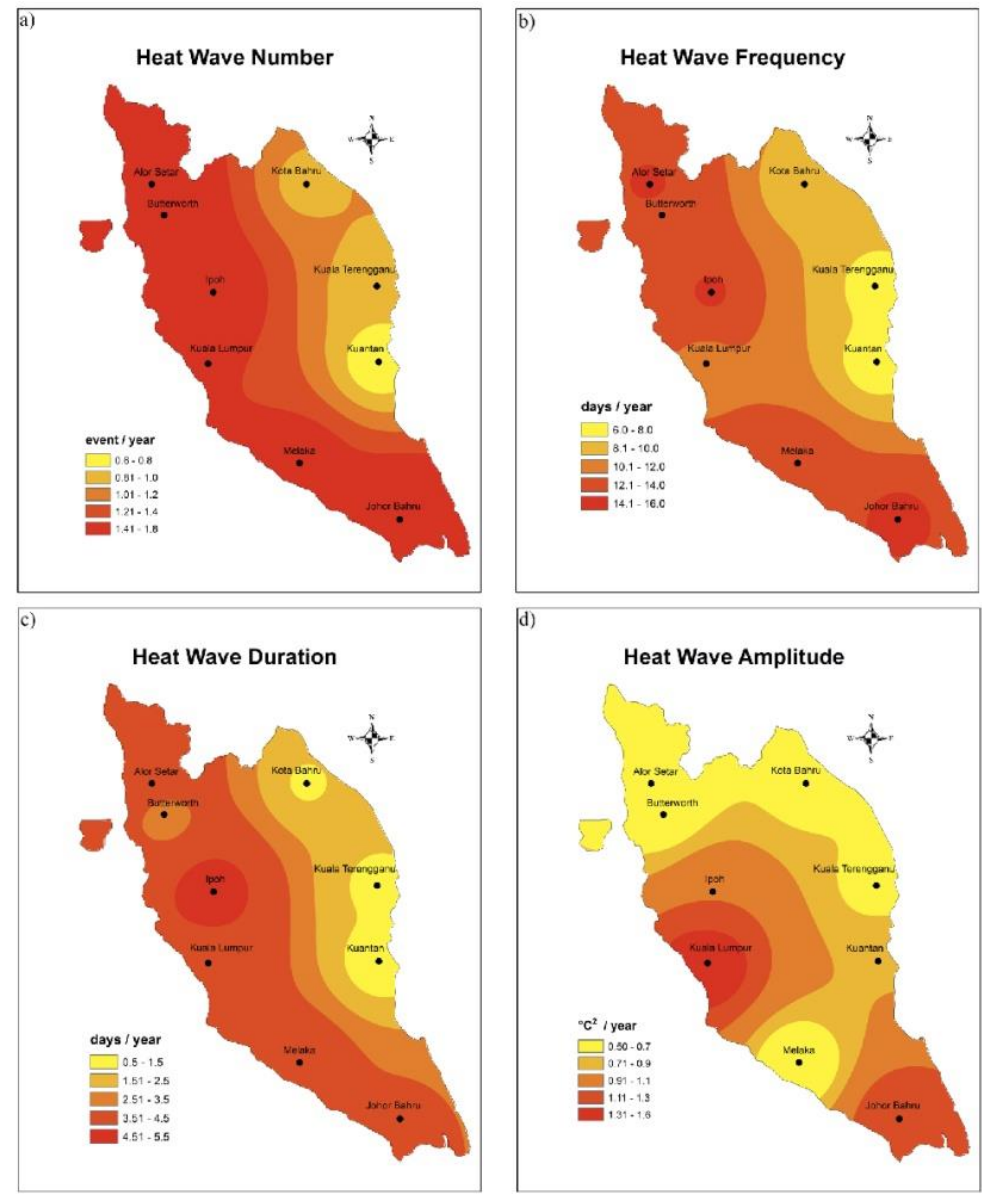

Fig. 4. Spatial pattern of heat wave characteristic over Peninsular Malaysia (a) heat wave number (b) heat wave frequency (c) heat wave duration, and (d) heat wave amplitude.

Based on the result represented by 95 percentile, HWD, HWF, and HWN, most of the station are resulting in longer duration of heat wave events which more than a week. This condition of the heat wave in Peninsular Malaysia can induce to affect public health especially during SWM and El Nino events. More than that, the higher value in HWA indices will have a greater impact on agriculture, which usually due to high values of evapotranspiration associated with the lack of precipitation (Croitoru et al., 2016). The yields can be severely affected when crop exposed to stressful condition during heat waves, mainly due to the lack of water in the irrigation system during the drought season. Over the study period, the range of heat wave amplitude for all locations is between $29.4^{\circ} \mathrm{C}$ and $33.0^{\circ} \mathrm{C}$. Compared to the optimum annual temperature for the major economic crops in Malaysia (NC2, 2000) in Table 3, we can assume that the heat wave events during the study period affected some agriculture plants, especially crop production. 
Table 3.

Optimum annual temperature of the major economic crop in Malaysia (Malaysia Second National Communication, 2000).

\begin{tabular}{cc}
\hline Crop & Optimum Annual Temperature \\
\hline Oil Palm & $22^{\circ} \mathrm{C}-32^{\circ} \mathrm{C}$ \\
Rice & $24^{\circ} \mathrm{C}-34^{\circ} \mathrm{C}$ \\
Rubber & $23^{\circ} \mathrm{C}-30^{\circ} \mathrm{C}$ \\
Cocoa & $25^{\circ} \mathrm{C}-32^{\circ} \mathrm{C}$ \\
\hline
\end{tabular}

\section{CONCLUSIONS}

This paper has successfully characterized the heat wave events in Peninsular Malaysia based on daily maximum and minimum temperature during the period 2001-2010. The combined effect of excess heat $\left(\mathrm{EHI}_{\text {sig }}\right)$ and heat stress $\left(\mathrm{EHI}_{\mathrm{accl}}\right)$ were employed to obtain the EHF index. The result showed that the highest EHF index has happened at Kuala Lumpur in 2002 and the lowest was at Alor Setar in 2006. The most of the heat wave event was recorded during El Nino events especially during moderate El Nino in 2002 until 2005 and 2010. Based on HWD, HWF, HWN, and HWA, locations with the highest climatological values has been characterized and found that the southwest (Johor Bahru) and the west (Kuala Lumpur) of Peninsular Malaysia are the highest for HWN and HWF, and HWA, respectively. On the other hand, the longest duration of the heat wave (HWD) was found in Ipoh with 24 days. The characteristics of heat wave from EHF index was also compared to spatial distribution maps which shows that southeast, northeast and west part of Malaysia experience a more heat wave event during the study period.

The results of our investigation showed that the heat wave conditions in Peninsular Malaysia are anxiously, and therefore, critical study and exploration is needed because this event has a direct impact on agriculture, economic, and human health. Under these circumstances, further research needs to be undertaken in order to produce standard definition and threshold heat wave for Malaysia. This information would be useful for health policymakers to enable them to better plan for future climate change impacts. The use of longer-term period would possible to give more accurate information about the occurrence of heat wave indices and events overall Malaysia.

\section{ACKNOWLEDGMENTS}

We would like to thank the Malaysia Meteorological Department for providing the temperature data. The second author is $\mathrm{PhD}$ candidate and supported by the Faculty Science and Natural Resources, University of Malaysia Sabah, 88400, Kota Kinabalu, Sabah.

\section{R E F E R E N C E S}

Abul, Q. A. \& Gazi, M. A. (2016) The impact of El-Niño on agro-economics in Malaysia and the surrounding regions: An analysis of the events from 1997-98. Asian J. Earth Sci., 9, 1-8.

Anderson, G. B. \& Bell, M. L. (2011) Heat wave in the United States: Mortality risk during heat wave and effect modification by heat wave characteristics in 43 U.S. communities. Environmental Health Perspectives, 119, 210-218.

Bocancea, R. S. (2018), "Heat waves frequency: a study case of Iasi City, Romania (1961-2016). Geographia Technica, 13(1), 10-19.

Coates, L., Haynes, K., O’Brien, J., McAneney, J., \& De Oliveira, F. D. (2014) Exploring 167 years of vulnerability: an examination of extreme heat events in Australia 1844-2010. Environmental Science \& Policy, 42, 33-44. 
Coumou, D. \& Rahmstorf, S. (2012) A decade of weather extremes. Nature Climate Change, 2(7), 491-496.

Croitoru, A. E., Piticar, A., Ciupertea, F. A. \& Rosca, C. F. (2016) Changes in heat wave indices in Romania over the period 1961-2015. Global and Planetary Change, doi: 10.1016/j.gloplacha.2016.08.016.

Esmailnejad, M. (2016), The spatial analysis of heat waves in southeast of Iran a case study: Sistan and Baluchistan Province. Geographia Technica, 11(2), 50-60.

Fischer, E. M. \& Schar, C. (2010) Consistent geographical patterns of changes in high-impact European heatwaves. Nature Geoscience, 3, 398-403.

Fischer, E. M., Seneviratne, S. I., Luthi, D. \& Schar, C. (2007) Contribution of land-atmosphere coupling to recent European summer heat wave. Geophys. Res. Lett., 34, L06707.

Guyton, A. C. \& Hall, J. E. (2000) Textbook of medical physiology 10th ed. Philadelphia, PA: W. B. Saunders Company.

Intergovernmental Panel on Climate Change (IPCC) in Climate Change 2013: Summary for Policymakers (Eds Stocker, T.F. et al.) (Cambridge University Press, 2013).

Keggenhoff, I., Elizbarashvili, M. A. \& King, I. (2014) Heat Wave Events over Georgia since 1961: Climatology, Changes and Severity. Climate, 3, 308-328.

Makerami, N., Salleh, E., Jaafar, M. Z. \& Ghaffarian, H. A. (2012) Thermal comfort conditions of shaded outdoor spaces in hot and humid climate of Malaysia. Building and Environment, 48, 7-14.

Malaysia's Second National Communication (NC2) Vulnerability \& Adaptation Assessment. (Ministry of Natural Resources and Environment Malaysia 2000).

Malaysia Meteorological Department (MMD), (2009) Climate change scenarios for Malaysian 20012099. (Malaysian Metrological Department, Scientific Report January 2009).

Mohd Salleh, N. H., Hasan, H. \& Kassim, S. (2015) Trends in Temperature Extremes across Malaysia. Advances in Environmental Biology, 9 (27), 174-181.

Nairn, J. R., Fawcett, R. G., \& Ray, D. (2009) Defining and predicting excessive heat events, a national system. In: Proc. Third Cent. Aust. Weather Clim. Res. Underst. High Impact Weather.

http://www.cawcr.gov.au/events/modelling_workshops/workshop_2009/papers/NAIRN.pdf. Accessed on 20 February 2019.

Nairn, J. R. \& Fawcett, R. G. (2013) Defining heatwaves: heatwave defined as a heat-impact event servicing all community and business sectors in Australia. http://www.cawcr.gov.au/publications/technicalreports/CTR_060.pdf. Accessed on 20 February 2019.

Nairn, J. R. \& Fawcett, R. G. (2015) The excess heat factor: a metric for heatwave intensity and its use in classifying heatwave severity. Int. J. Environ. Res. Public Health, 12, 227-253.

Peng, R. D., Boob, J. F., Tebaldi, C., McDaniel, L., Bell, M. L., \& Dominici, F. (2011) Toward a quantitative estimate of future heat wave mortality under climate change. Environmental Health Perspectives, 119(5), 701-706.

Perkins, S. E. \& Alexander, L. V. (2013) On the measurement of heat wave. Journal of Climate, 26, 4500-4517, doi: 10.1175/JCLI-D-12-00383.1.

Tangang, F. T., Juneng, L., Salimun, E., Sei, K. M., Le, L. J., \& Muhamad, H. (2012) Climate change and variability over Malaysia: Gaps in science and research information. Sains Malaysiana, 41(11), 1355-1366.

Tertre Le, A., Lefranc, A., Eilstein, S., Declerc, C., Medina, S., Blanchard, M., Chardon, B., Fabre, P., Filleul, L., Juso, J. F., Pascal, L., Prouvost, H., Cassadou, S. \& Ledrans, M. (2006) Impact of the 2003 heatwave on all-cause mortality in 9 French cities. Epidemiology, 17, 75-9.

Wai, N. M., Camerlengo, A., and Wahab, A. K. A. (2005) A Study of Global Warming in Malaysia. Jurnal Teknologi, 42, 1-10.

Zuo, J., Pullen, S., Palmer, J., Bennetts, H., Chileshe, N. \& Ma, T. (2014) Impacts of heat wave and corresponding measures: a review. Journal of Cleaner Production, 92 (1-12). http://dx.doi.org/10.1016/j.jclepro.2014.12.078. 